was one callin on CMA to oppose "adoption of Bill C-484 and of any legislation would result in compromising access for women the medical services required to terminate a pregnancy." The bill would "implicitly confer legal status on the fetus" and its adoption could open the door to all kinds of claims or court actions calling for the re-criminalization of abortion, said motion sponsor Dr. Paul Robinson.

Another motion will oblige CMA to lobby for "appropriate 'Apology' legislation in all Canadian jurisdictions," which would allow doctors to express regret about adverse events without incurring medico-legal risk.

\section{President-elect puts patients first}

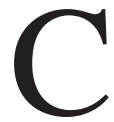
anadian doctors must be the "authoritative voice" that speaks for patients, says Saskatchewan family physician and CMA President-elect Dr. Anne Doig.

"Moreover, our voices must be loudest for those who cannot speak for themselves: our poor, our children and our elderly," said Doig, who will assume the helm at the 2009 general council in Saskatoon, Saskatchewan.

Patient advocacy and sustainable funding for health care will be among her priorities. "Physicians must lead the changes necessary to sustain our publicly funded health care system," she said.

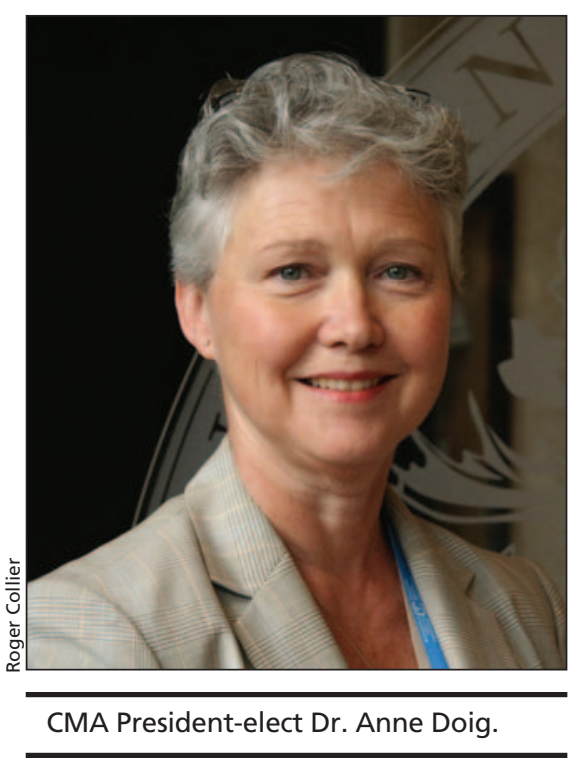

Doig has chaired the CMA's Committee on Bylaws. She also teaches in the Department of Obstetrics and Gynecology at the University of Saskatchewan.

\section{Mental health prejudices}

$\mathrm{D}$ octors are at least as guilty of discriminating against people with mental illnesses as the general population, according to the chair of the Mental Health Commission of Canada.

"One of the first targets for our antistigma campaign is health care professionals," former Senator Michael Kirby told the CMA General Council on Aug. 18, 2008. "You'd think that health care workers would be less prejudiced about mental illness than the general population. You would be wrong."

Delegates later passed motions call- ing on the CMA to work with the Mental Health Commission of Canada to: develop a national strategy for mental health; develop a 5-year plan to improve access to psychiatric care and reduce stigma; and establish benchmarks for access to psychiatric care and treatment in rural and remote areas. They also called on governments to improve coordination of mental health services for children.

Doctors must also "accept and have the courage to take care of ourselves as physicians," said Dr. Jean-Bernard Trudeau, president of the Quebec Medical Association, who noted that 37\% of doctors go through a depressive episode while in training. To that end, the CMA was urged to develop a strategy to support the mental health of Canada's doctors. - Ann Silversides and Roger Collier, CMAJ

DOI:10.1503/cmaj.081317

\title{
Patient-based funding model endorsed
}

An earlier version of this article was published at www.cmaj.ca on Aug. 20, 2008.

$\mathrm{T}$ he Canadian Medical Association has thrown its weight behind patient-based funding of the health care system.

To that end, the association will develop a "blueprint and a timeline" for the transformation of the system to include patient-focused funding. Delegates to the CMA's 141st annual general council in Montreal, Quebec on Aug. 19, 2008, approved a resolution sponsored by incoming President Dr. Robert Ouellet calling on the CMA to develop such a plan by February, 2009.

Delegates also passed a general motion in support of a patient-based model of funding.

But Canadian Doctors for Medicare Chair Dr. Danielle Martin says the motions are far too broad. "Do we interpret that as opening up the health care system to private competition?"

Tying funding to patients may help in some areas, Martin says. But it comes with risks, including lower quality, reduced accessibility, reduced efficiency and higher costs. "To imply it will solve all the problems in Canada's health care system is stretching."
Former Quebec health minister Claude Castonguay, author of a February 2008 study commissioned by the Quebec government which concluded that money should "follow the patient," told delegates that Canada lags behind many nations in reforming its system.

The majority of member countries in the Organisation for Economic Cooperation and Development have already implemented some form of patient-based funding, Castonguay said, adding that activity-based funding would reward hospitals performing at a high level and give poor performing hospitals an incentive to improve.

Canadian hospitals currently receive money via a block-funding model, which grants annual lump sums. But many other countries - such as the United States and England - have implemented funding systems in which hospitals are rewarded on the basis of patient outcomes (called payment by results or pay for performance) or activity-based funding (CMAJ 2008;178[11]:1207-8). — Roger Collier, CMAJ

DOI:10.1503/cmaj.081314 